\title{
Tympanoplasty success based on surgeon and patient-reported outcomes perspectives: a 10-year review in a tertiary center
}

\author{
M. Tshifularo* (1)
}

\begin{abstract}
Background: The latest international trends in healthcare put more emphasis on patients' perspectives in reporting success in surgical procedures. A holistic approach in measuring surgical outcomes, defined as global success, should include the patient's perioperative experiences, expectations, and outcome measures. In published literature, surgeons propose several definitions of post-operative successful surgical outcomes following tympanoplasty. Most surgical outcomes and the surgeon's definition of success exclude the patient's perspectives. Patient-reported outcomes would allow surgeons to understand and measure the benefit of the several procedures performed from the perspective of the patients. Current definitions of successful tympanoplasty do not capture patient reported outcomes which are important to patients. A divergence is frequently found between outcomes relevant to the patient and to the surgeon. Patient-reported outcomes would complement traditionally measured clinical outcomes by the surgeon to give a true global outcome measuring success. The main aim of the current study was to propose a definition of true global success following tympanoplasty by combining the patient's and the surgeon's reported satisfaction rate based on the indication and the goals for the operation.
\end{abstract}

Results: A total of 128 procedures were performed on 128 ears in 125 patients, of which $52 \%(n=57)$ were done on the right and $48 \%(n=61)$ on the left side. There was no significant difference between the two groups $(p=0.07)$. There was a female preponderance, with $62 \%$ females and $44 \%$ males ( $p=0.105)$. The majority of patients, $63 \%$ $(n=68)$, were between the age of 26 and 45 years, while 19\% $(n=20)$ fell into the 46 - to 60-year age range, with no significant difference between the groups $(p=0.21)$. There was complete graft take in $77 \%(107 / 128)$ of the ears in whereas 23\% (21/128) of the ears the graft had not taken at the 6-month follow-up period. The true global success satisfaction rate was $92 \%$ (chi-square test $=119 ; p=0.001$ ) compared to the $77 \%$ surgical success.

Conclusion: In assessing success in tympanoplasty, the patient- and surgeon-reported outcomes, when considered against agreed goals and indications, correlate well statistically. In this cohort, the true global success satisfaction rate was $92 \%$ (chi-square test $=119 ; p=0.001<0.05$ ) compared to $77 \%$ surgical success, based on graft take only. The combination of patient- and surgeon-reported outcomes would be beneficial in reporting true global success in tympanoplasty.

Keywords: Tympanoplasty, Global success outcome, Patient-reported outcome, Surgeon-reported outcome, Success factors, Satisfaction rate

*Correspondence: mashudu.tshifularo@up.ac.za Steve Biko Academic Hospital, ENT Department, University of Pretoria, Private Bag X 169, Pretoria 0001, South Africa

\section{Background}

The latest international trends in healthcare put more emphasis on patients' perspectives in reporting success in surgical procedures. A holistic approach outcome measure in surgery, defined as global success, should 
include patient perioperative experiences, expectations, and outcome measures [1]. In published literature, surgeons propose several definitions of post-operative successful surgical outcomes following tympanoplasty. Most surgical outcomes and the surgeon's definition of success exclude the patient's perspectives. Patient-reported outcomes (PRO's) allow surgeons to understand and measure the benefit of the several procedures performed from the patient's perspective $[1,2]$. The surgeon's clinical outcome goals of procedures do not always capture aspects of health which are important to patient. A divergence is frequently found between outcomes relevant to patient and to surgeon. PRO's complement traditionally measured clinical outcomes and where combined give a true global outcome measure of success [1-3].

Tympanoplasty is a relatively common procedure performed by otologists for various indications, such as for the creation of a safe ear, restoration of normal anatomy (repair-perforated tympanic membrane), removal or eradication of disease, and for improvement of hearing [4]. The primary goal of tympanoplasty is the restoration of the integrity of the tympanic membrane [5]. The closure of uncomplicated tympanic membrane perforation is reported with as having a good success rate in literature [4-6]. Several studies report a success rate of 60 to $99 \%$ in adults and 35 to $94 \%$ in children $[6,7]$.

The definition of successful tympanoplasty varies between authors. Most authors report, as part of a successful surgical outcome, an intact tympanic membrane (graft take-up) by 6 months' post-operatively, associated with post-operative hearing improvement, air bone gap (ABG) closure, and middle ear aeration [8, 9]. Several prognostic factors are cited as responsible for the success of graft take-up [10]. Belluchi [11, 12] proposed a four-staged- and Wullstein a five-staged classification for prognostic success factors in tympanoplasty. Austin [13] proposed disease, stage categories, and disease descriptors. Black $[14,15]$ introduced the surgical, prosthetic, infection, tissues, and eustachian tube system (SPITE). Kartush [16] introduced the middle ear risk index (MERI). Becvarovski and Kartush [17, 18] developed MERI 200, emphasizing the effects of smoking on myringoplasty $[19,20]$.

Several techniques and materials used to repair the tympanic membrane are reported, with the main purpose being the stimulation of the skin and mucosal regeneration leading to permanent closure of the perforation [21]. A surgeon considers failures in tympanoplasty (clinical outcomes) to include blunting, lateralization of the graft, failure to close the perforation, thickening of the graft, iatrogenic cholesteatomas, eardrum retractions, and hearing loss. Researchers' opinions differ on the definition of a successful tympanoplasty. The main aim of the current study was to propose a global satisfaction success measuring system combining the patient's and the surgeon' reported outcome satisfaction and based on the indications and goals of the operation.

\section{Methods}

This study entailed a retrospective clinical audit of tympanoplasties performed by the researcher between February 2008 and February 2018 on patients followed up for 6 months and over postoperatively. The review was executed by a senior surgeon and researcher in the Department of Otorhinolaryngology. Ethics approval was obtained prior to the study. Clinical data on pre-operative consultations and 6 months post-operative observations was collected. Perforation size was classified as a percentage of the the tympanic area. A small perforation comprised less than $25 \%$, a medium perforation 25 to $50 \%$, and a large perforation over $50 \%$ of the drum area, respectively. The relationship between the graft take-up and all relevant prognostic factors in the literature were analyzed. The prognostic factors considered included etiology, status of the perforation (dry/wet/discharging), duration of a dry ear, status of the opposite ear, middle ear mucosal status at the time of the operation, materials used, surgical approach, surgical technique, place and size of perforation, patient's income per day, ossicular chain status, side (right or left), smoking history, comorbidities, diabetes mellitus, and human immunodeficiency virus (HIV) status.

Data was captured and analyzed using Epi info 3. 5. 1 (2008 version), USA. Descriptive statistics were used to summarize the data and to ascertain the percent contribution of the factors under study. A simple $t$ test was used to test the level of significance for each of the 12 factors under study. Chi-square test was applied to test the level of association between the surgeon's and the patients' level of satisfaction. A $p$ value of 0.05 was used to determine the level of significance. Further analysis was conducted using STATISTICA version 7.0, as well as Microsoft Excel, to generate graphs and tables.

The second reported outcome analysis of 125 tympanoplasty treated patients was evaluated using validated questionnaires to assess self-reported goals or variables, hearing improvement, ear discharge, pain, tinnitus, smell, patient satisfaction by the patients, and the surgeon's clinical outcomes.

The patient's satisfaction score of success was compared with the surgeon's score and analyzed based on the goals of the operation in 108 patients. A score of $<5$ represented unsatisfied, 5 to 10 satisfied, and $>10$ very satisfied outcomes.

The surgeon completed the questionnaire and patients' 6-month follow-up visit separately. 


\section{Results}

The final dataset contained 128 procedures performed on 128 ears in 125 patients, with 67 of the procedures (52\%) done on the right and 61 procedures $(48 \%)$ on the left side $(p=0.07)$ (Figs. 1 and 2). The procedures done on the left and on the right did not differ significantly. There were $55(44 \%)$ male and 77 (62\%) were female patients with no significant difference between the groups $(p=0.105)$ (Fig. 3). The majority of the patients, 63\% (68/125), were between the age of 26 and 45 years, while 19\% (20/125) were between 46 and 60 years of age. The age groups did not differ significantly ( $p=0.14$ ) (Fig. 4). The average age group was $26-45$ years. A perforation size of $>50 \%$ was found in $56 \%(72 / 128)$ of the ears and a perforation size of $<50 \%$ was present in $44 \%(56 / 128)$. There was no significant difference between the two groups $(p=0.079)$ (Fig. 5). The perforation site was central in the majority of the cases, $70 \%(89 / 128)$, posterior in $23 \%$ (30/128), and anterior in $7 \%(9 / 128)$ of the ears, respectively. However, the different sites of the perforations did not differ significantly ( $p=0.21)$ (Fig. 6). Complete graft take occurred in $77 \%(107 / 128)$ of the ears, but in $23 \%(21 / 128)$, there graft had not taken at the 6-month follow-up period.

\section{Site of perforation}

The site of the perforation was significant to healing $(p=0.03)$ (Table 1). Perforations were classified according to site into anterior, posterior, and central perforations. Anterior perforations had a relatively poor graft take at $58 \%$, posterior perforations had a good graft take at $83 \%$, but the best results were found in central perforations which had a graft take of $95 \%$.

\section{Middle ear mucosa status}

The status of the middle ear mucosa was significant to healing $(p$ value $=0.02)$. A dry normal middle ear showed

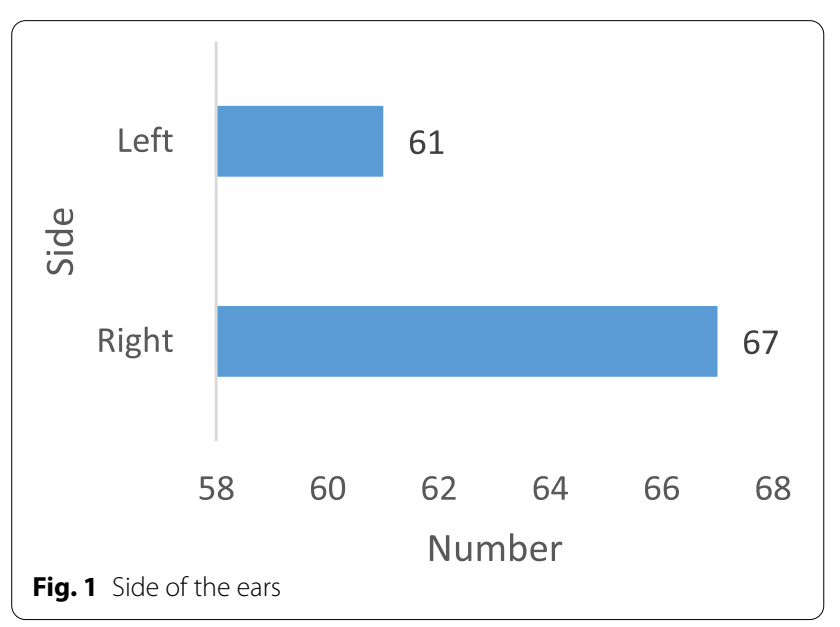

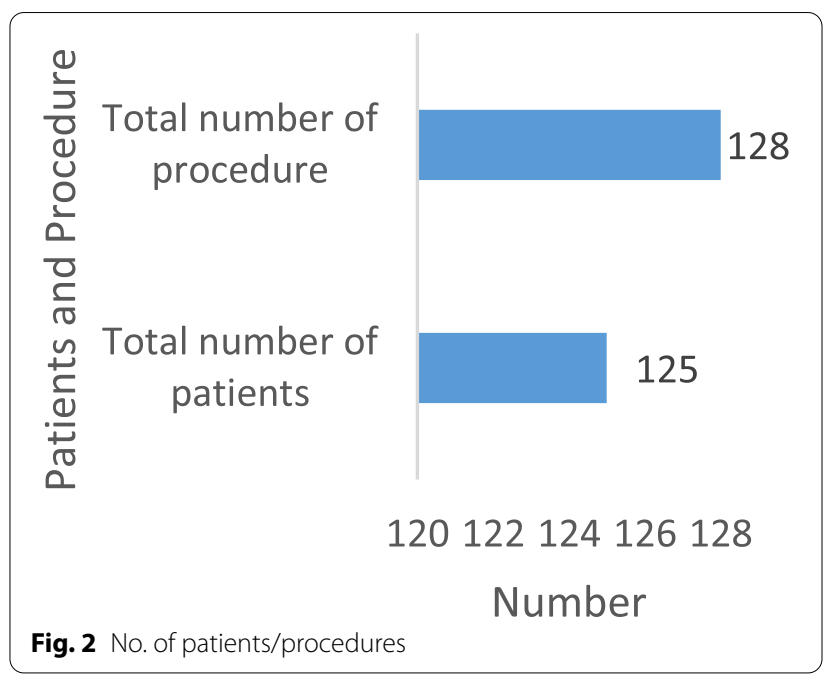

a graft take rate of $61 \%$, but in the presence of granulations, this rose to $83 \%$. A discharging ear with granulations had a graft take of $61 \%$, while wet and moist ears had a graft take of $83 \%$. Fibrous adhesions did not prevent healing, with a $100 \%$ graft take. The presence of cholesteatoma hindered healing, with only $14 \%$ of the grafts taking.

\section{Status of contralateral ear}

In the presence of a normal contralateral ear the graft take was $69 \%$ and in the presence of an infected contralateral ear the graft take was $68 \%$.

\section{Income status}

The graft take was $71 \%$ in patients living on less than $<2$ US Dollars (\$) per day and 67\% in patients living above US\$2 per day.

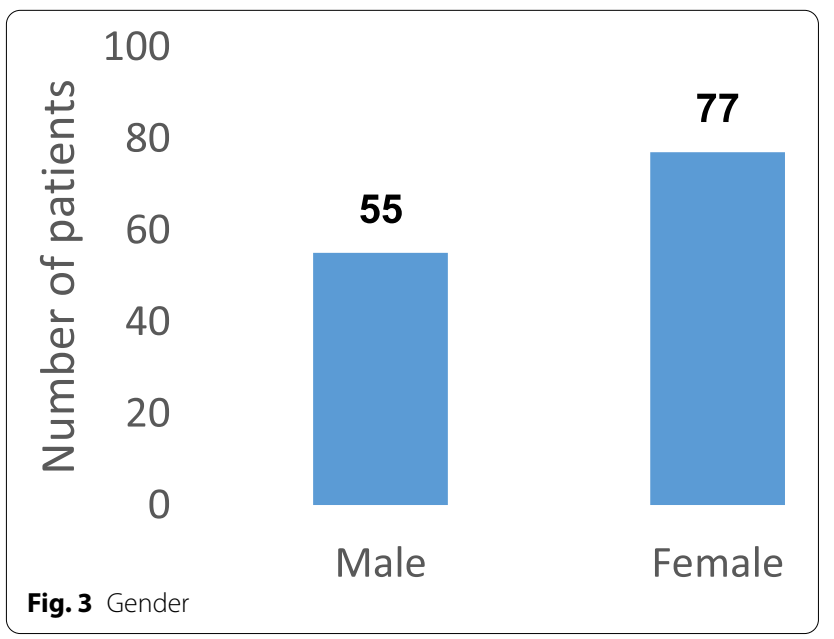




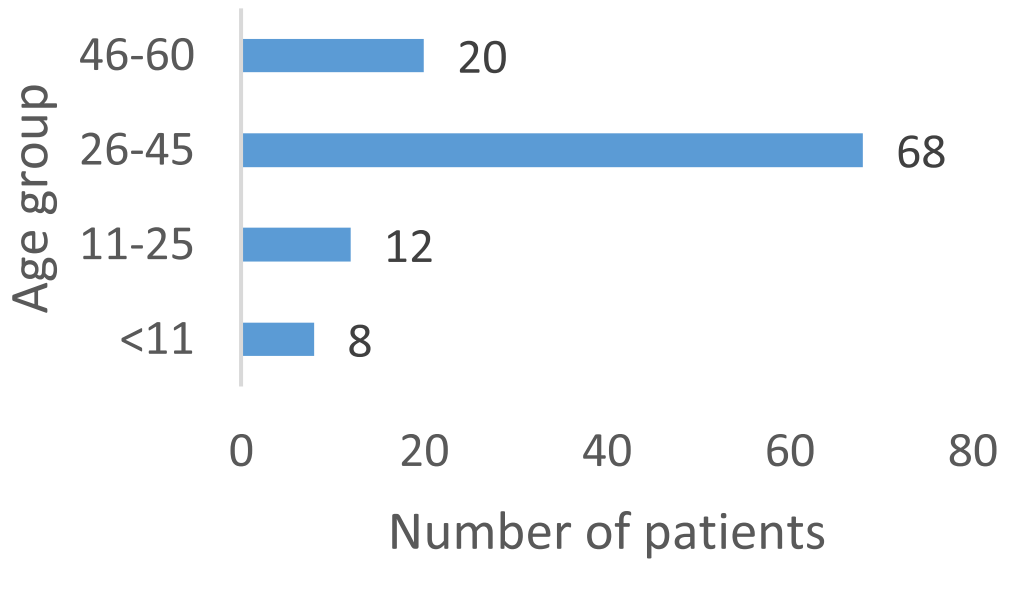

Fig. 4 Age group

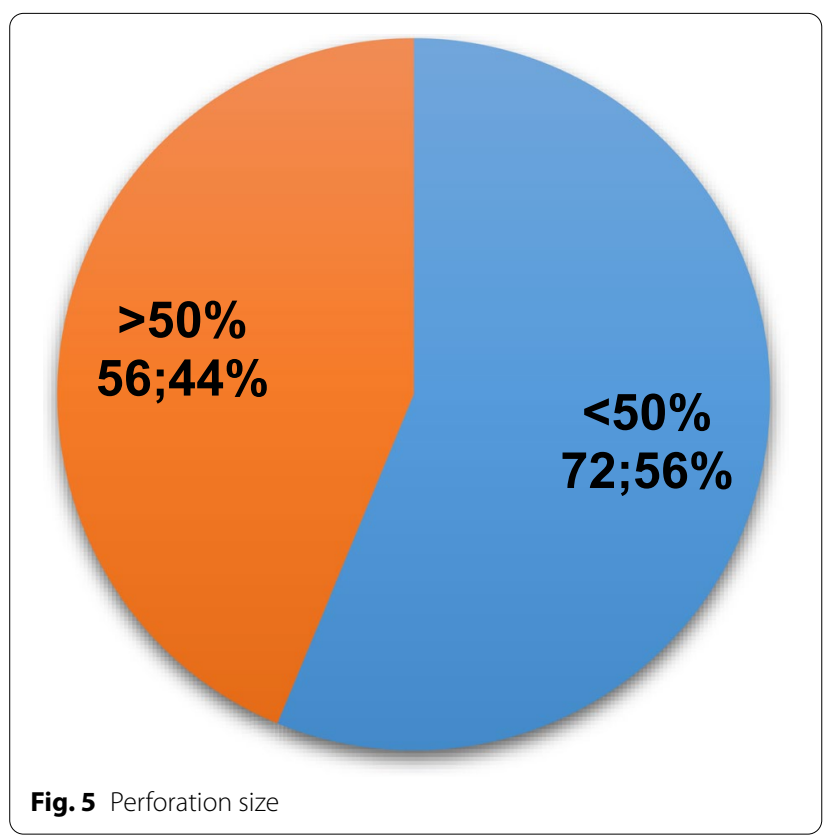

\section{Technique}

A significant difference in graft take was noted depending on surgical technique $(p=0.04)$. The sandwich technique gave the highest graft take at $86 \%$, followed by the onlayunderlay technique at $83 \%$, then the underlay technique at $77 \%$ and last by the onlay technique at $67 \%$ graft take.

\section{Surgical approach}

There was a significant difference in graft take depending on the surgical approach $(p=0.01)$. The canal approach gave the best results with a graft take of $77 \%$, followed by $69 \%$ the post auricular approach at $69 \%$ and lastly the endaural approach at $64 \%$.

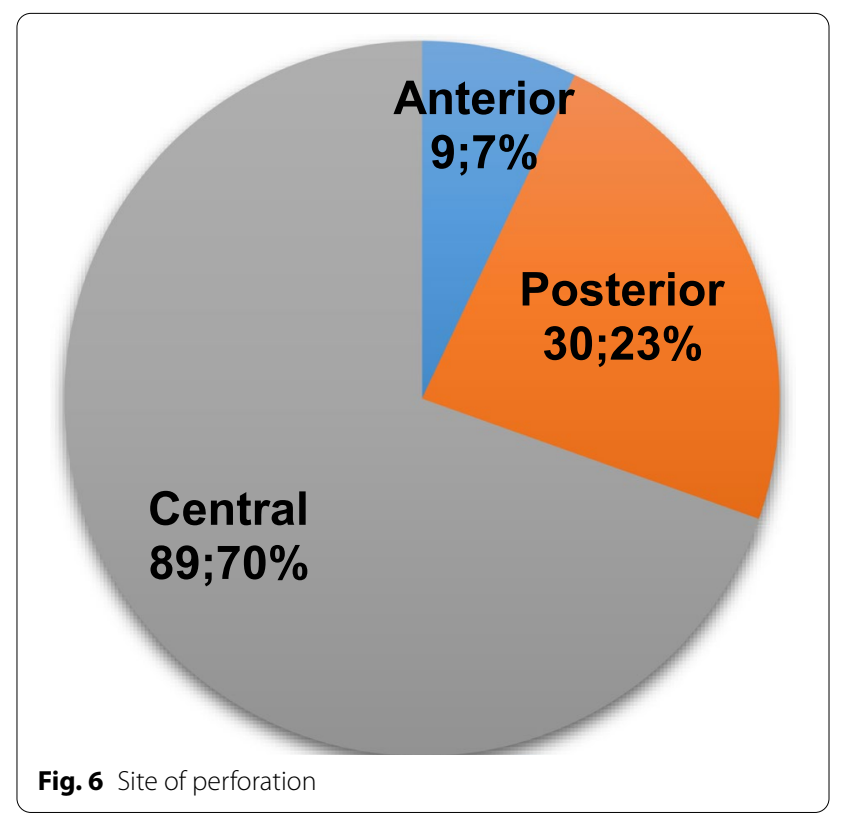

\section{Antral drainage}

In the cases where antral drainage was done, there was a graft take of $67 \%$ and where it was not done the graft take was $70 \%$.

There was not significant difference in drum take up between the following prognosic factors presented in Table 2.

Perforations with a size less than $50 \%$ of the drum had a graft take of $83 \%$ while perforations with a size greater than $50 \%$ of the drum had a graft take of $57 \%(p=0.276)$. There was no significant difference in healing between the different graft materials used, whether fascia, cartilage, perichondrium, or combination $(p=0.073)$. There 
Table 1 Success prognostic factors in the current study: significant variables

\begin{tabular}{|c|c|c|c|c|}
\hline Prognostic factors & $\begin{array}{l}\text { Number of ears in } \\
\text { category }\end{array}$ & $\begin{array}{l}\text { Number of ears successfully } \\
\text { repaired }\end{array}$ & Success rate (\%) & $P$ value \\
\hline Site of perforation & & & & 0.03 \\
\hline Anterior & 12 & 7 & $58 \%$ & \\
\hline Posterior & 40 & 33 & $83 \%$ & \\
\hline Central & 21 & 20 & $95 \%$ & \\
\hline Middle ear mucosa status & & & & 0.002 \\
\hline Dry normal & 31 & 19 & $61 \%$ & \\
\hline Granulation & 6 & 5 & $83 \%$ & \\
\hline Granulation, discharging & 23 & 14 & $61 \%$ & \\
\hline Wet & 1 & 1 & $100 \%$ & \\
\hline Wet moist & 36 & 30 & $83 \%$ & \\
\hline Fibrous adhesions & 4 & 4 & $100 \%$ & \\
\hline Cholesteatoma & 3 & 1 & $14 \%$ & \\
\hline Status of contralateral ear & & & & 0.04 \\
\hline Normal & 89 & 61 & $69 \%$ & \\
\hline Infected & 19 & 13 & $68 \%$ & \\
\hline Income status & & & & 0.02 \\
\hline$<2$ Dollar (\$) & 51 & 36 & $71 \%$ & \\
\hline >2 Dollar (\$) & 58 & 38 & $67 \%$ & \\
\hline Technique & & & & 0.04 \\
\hline On lay & 9 & 6 & $67 \%$ & \\
\hline Under lay & 66 & 51 & $77 \%$ & \\
\hline Sandwich & 7 & 6 & $86 \%$ & \\
\hline On lay-underlay & 12 & 10 & $83 \%$ & \\
\hline Surgical approach & & & & 0.01 \\
\hline End aural & 33 & 21 & $64 \%$ & \\
\hline Auricular & 62 & 43 & $69 \%$ & \\
\hline Canal & 13 & 10 & $77 \%$ & \\
\hline Antral drainage & & & & 0.02 \\
\hline Not done & 69 & 48 & $70 \%$ & \\
\hline Done & 39 & 26 & $67 \%$ & \\
\hline
\end{tabular}

was no significant difference between patients with comorbidities (diabetic mellitus, HIV) and those without $(p=0.082)$. Non-smokers had a graft take of $69 \%$ while smokers were at $50 \%$ ( $p$ value of 0.089 ). Iatrogenic perforations had a graft take of $100 \%$ compared to traumatic perforations at $78 \%$ and perforations following infection had a take rate of $68 \%$ ( $p$ value $=0.051)$.

\section{Surgical outcome satisfaction}

The results show that in the areas assessed in the satisfaction questionnaire, the surgeon was not satisfied with the surgical results in 24 cases, was satisfied in 36 cases, and very satisfied in 48 cases. In comparison, the patients were not satisfied in 17 areas, satisfied in 42 areas, and very satisfied in 49 areas assessed in the satisfaction questionnaire (Table 3). The greatest agreement between surgeon and patients was in the "very satisfied" category, where there was almost identical scores, 43 each for drum repair, 3 each on hearing improvement, and 2 versus 3 respectively on stopping pain (Tables 3 and 4).

Looking at the results per activity, there is significance difference between not satisfied to very satisfied between the patients and the surgeon (Table 4). The results show that the level of satisfaction for both surgeon and patient differed significantly between the not satisfied, satisfied, and very satisfied categories $(t=2.0150 ; p=0.0037)$. Hearing improvement was $(t=2.0150 ; p=0.0088$; stopping discharge was $t=2.0150 ; p=0.0164$ and stopping pain was $t=2.1318 ; p=0.0030$. This shows that Patients and Surgeon were very satisfied with Drum Repair (patient $=88 \%$ and surgeon $=90 \%$ ) compared to hearing improvement (patient $6 \%$ and surgeon=6\%), stop discharge (both patient and surgeon $=0 \%$ ), and stop pain (patient $=6 \%$ and surgeon $=4 \%$ ). These confirms 
Table 2 Success prognostic factors in the current study: factors with no significance

\begin{tabular}{|c|c|c|c|c|}
\hline Prognostic factors & Number of ears in category & $\begin{array}{l}\text { Number of ears successfully } \\
\text { repaired }\end{array}$ & Success rate (\%) & $P$ value \\
\hline Perforation size & & & & 0.276 \\
\hline$<50 \%$ & 60 & 50 & $83 \%$ & \\
\hline$>50 \%$ & 42 & 24 & $57 \%$ & \\
\hline Graft material & & & & 0.073 \\
\hline Fascia & 91 & 66 & $73 \%$ & \\
\hline Cartilage & 6 & 4 & $67 \%$ & \\
\hline Perichondrium & 2 & 2 & $100 \%$ & \\
\hline Combination & 3 & 2 & $67 \%$ & \\
\hline Comorbidity & & & & 0.082 \\
\hline Diabetic & 2 & 0 & $0 \%$ & \\
\hline HIV & 3 & 2 & $67 \%$ & \\
\hline None & 103 & 72 & $70 \%$ & \\
\hline Smoking & & & & 0.089 \\
\hline Non-smoker & 106 & 73 & $69 \%$ & \\
\hline Smoker & 2 & 1 & $50 \%$ & \\
\hline Aetiology & & & & 0.051 \\
\hline Trauma & 9 & 7 & $78 \%$ & \\
\hline Infection & 78 & 53 & $68 \%$ & \\
\hline latrogenic & 7 & 7 & $100 \%$ & \\
\hline
\end{tabular}

Table 3 Surgical outcome satisfaction score

\begin{tabular}{|c|c|c|c|c|c|c|c|c|}
\hline \multicolumn{3}{|c|}{ Surgical outcome satisfaction } & \multirow{2}{*}{$\begin{array}{l}\text { Repair drum } \\
16\end{array}$} & \multirow{2}{*}{$\begin{array}{l}\begin{array}{l}\text { Hearing } \\
\text { improvement }\end{array} \\
3 \\
\end{array}$} & \multirow{2}{*}{$\begin{array}{l}\text { Stop discharge } \\
3\end{array}$} & \multirow{2}{*}{$\begin{array}{l}\text { Stop pain } \\
2\end{array}$} & \multirow{2}{*}{$\begin{array}{l}\text { Others } \\
0\end{array}$} & \multirow{2}{*}{\begin{tabular}{|l|} 
Total \\
24
\end{tabular}} \\
\hline Not satisfied & Doctor & Freq & & & & & & \\
\hline & & $\%$ & $67 \%$ & $13 \%$ & $13 \%$ & $8 \%$ & $0 \%$ & $100 \%$ \\
\hline & Patient & Freq & 10 & 2 & 2 & 3 & 0 & 17 \\
\hline & & $\%$ & $59 \%$ & $12 \%$ & $12 \%$ & $18 \%$ & $0 \%$ & $100 \%$ \\
\hline \multirow[t]{4}{*}{ Satisfied } & Doctor & Freq & 17 & 9 & 3 & 6 & 1 & 36 \\
\hline & & $\%$ & $47 \%$ & $25 \%$ & $8 \%$ & $17 \%$ & $3 \%$ & $100 \%$ \\
\hline & Patient & Freq & 23 & 10 & 4 & 4 & 1 & 42 \\
\hline & & $\%$ & $55 \%$ & $24 \%$ & $10 \%$ & $10 \%$ & $2 \%$ & $100 \%$ \\
\hline \multirow[t]{4}{*}{ Very satisfied } & Doctor & Freq & 43 & 3 & 0 & 2 & 0 & 48 \\
\hline & & $\%$ & $90 \%$ & $6 \%$ & $0 \%$ & $4 \%$ & $0 \%$ & $100 \%$ \\
\hline & Patient & Freq & 43 & 3 & 0 & 3 & 0 & 49 \\
\hline & & $\%$ & $88 \%$ & $6 \%$ & $0 \%$ & $6 \%$ & $0 \%$ & $100 \%$ \\
\hline \multirow[t]{4}{*}{ Total } & Doctor & Freq & 76 & 15 & 6 & 10 & 1 & 108 \\
\hline & & $\%$ & $70 \%$ & $14 \%$ & $6 \%$ & $9 \%$ & $1 \%$ & $100 \%$ \\
\hline & Patient & Freq & 76 & 15 & 6 & 10 & 1 & 108 \\
\hline & & $\%$ & $70 \%$ & $14 \%$ & $6 \%$ & $9 \%$ & $1 \%$ & $100 \%$ \\
\hline
\end{tabular}

that both patient and surgeon's level of satisfaction were excellent $92 \%$. The results of the chi-square test are found in Table 5.

There was a significant association between patient and surgeon level of satisfaction. The chi-square test results confirm that the level of satisfaction the patients expressed also correlates with the level of satisfaction by the surgeon and that the level of dissatisfaction the patients had correlates with the level of dissatisfaction the surgeon expressed (Fig. 7). 
Table 4 Results on satisfaction patient/surgeon

\begin{tabular}{|c|c|c|c|c|c|}
\hline & Repair drum & Hearing improvement & Stop discharge & Stop pain & Total \\
\hline Surgeon not satisfied & 16 & 3 & 3 & 2 & 24 \\
\hline Patient not satisfied & 10 & 2 & 2 & 3 & 17 \\
\hline Surgeon satisfied & 17 & 9 & 3 & 6 & 35 \\
\hline Patient satisfied & 23 & 10 & 4 & 4 & 41 \\
\hline Surgeon very satisfied & 43 & 3 & 0 & 2 & 48 \\
\hline Patient very satisfied & 43 & 3 & 0 & 3 & 49 \\
\hline Total surgeon & 76 & 15 & 6 & 10 & 107 \\
\hline Total patient & 76 & 15 & 6 & 10 & 107 \\
\hline ttest & 2.0150 & 2.0150 & 2.0150 & 2.1318 & \\
\hline pvalue & 0.0037 & 0.0088 & 0.0164 & 0.0030 & \\
\hline
\end{tabular}

Table 5 Satisfaction level of patients and surgeon

\begin{tabular}{|c|c|c|c|c|c|c|c|c|c|}
\hline & & \multicolumn{8}{|l|}{ Patient } \\
\hline & & \multicolumn{2}{|l|}{ Not satisfied } & \multicolumn{2}{|l|}{ Satisfied } & \multicolumn{2}{|l|}{ Very satisfied } & \multicolumn{2}{|l|}{ Total } \\
\hline & & Frequency $(n)$ & $\%$ & Frequency $(n)$ & $\%$ & Frequency $(n)$ & $\%$ & Frequency $(n)$ & $\%$ \\
\hline \multirow[t]{5}{*}{ Surgeon } & Not satisfied & 15 & $88 \%$ & 9 & $21 \%$ & 0 & $0 \%$ & 24 & $22 \%$ \\
\hline & Satisfied & 2 & $12 \%$ & 30 & $71 \%$ & 4 & $8 \%$ & 36 & $33 \%$ \\
\hline & Very satisfied & 0 & $0 \%$ & 3 & $7 \%$ & 45 & $92 \%$ & 48 & $44 \%$ \\
\hline & Total & 17 & $100 \%$ & 42 & $100 \%$ & 49 & $100 \%$ & 108 & $100 \%$ \\
\hline & Chi-square & & $p$ value & $x$-critical & & Significant & Cramer V & & \\
\hline Pearson's & 119.6754 & & $6.27 \mathrm{E}-25$ & 9.487729 & & Yes & 0.744347 & & \\
\hline
\end{tabular}

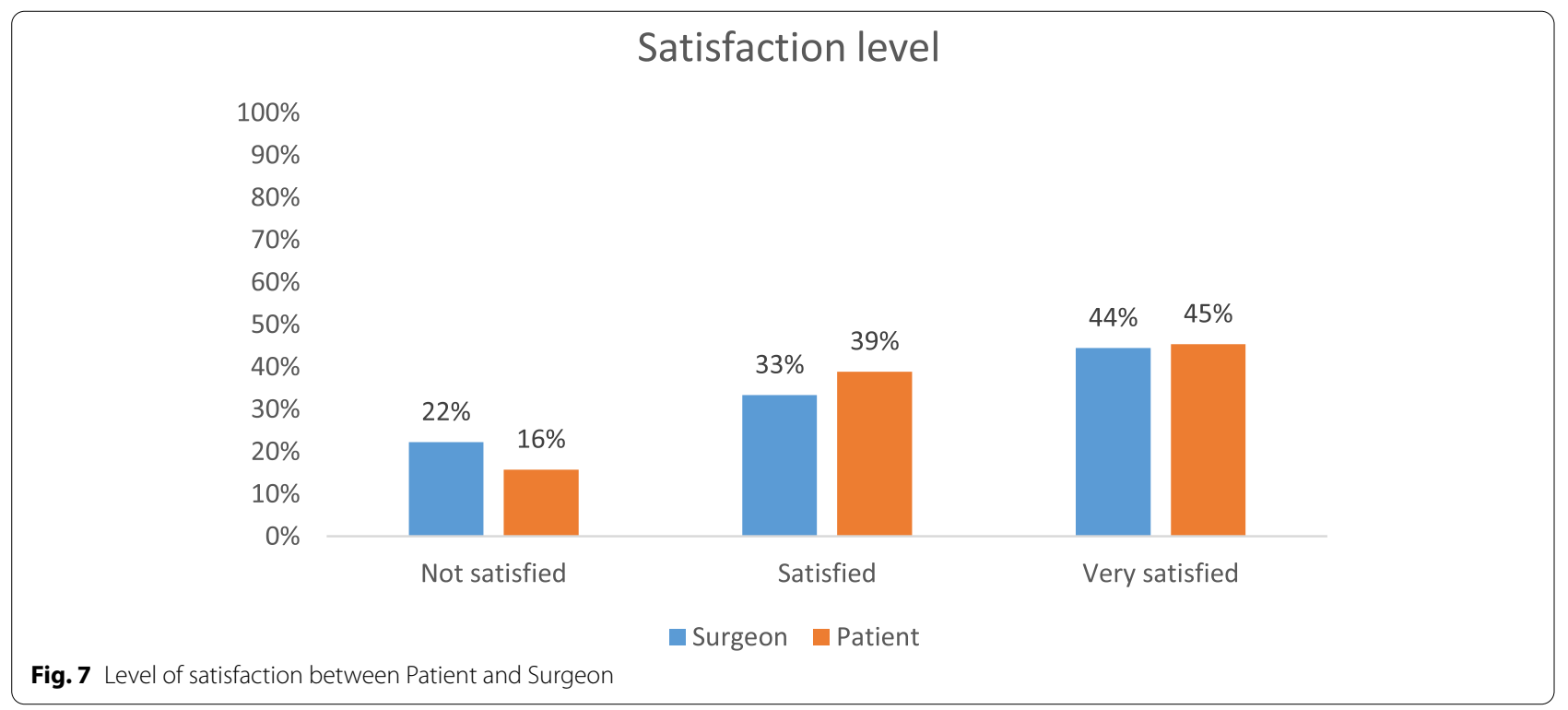

\section{Discussion}

The definition of a successful tympanoplasty varies between authors. The principle factors affecting outcome are not only the clinically related but include both surgeon dependent (patient selection, experience, and technique) and patient dependent (general health, perforation aetiology, site and size, comorbidity, smoking) factors [14-17, 23].

Tympanoplasty is a general procedure performed by otologists regularly, though no agreement exists on 
success and prognostic factors (Table 6) $[4-7,10,11]$. In this study, the successful graft take depended on various prognostic factors, some statistically significant and some not. The factors reviewed in the current study that were found to make a significance impact to graft take included site of perforation, middle ear mucosa status, status of contralateral ear, income status, technique, surgical approach, and antral drainage. Age was another statistically significant factor.

Age, less than 8 years, held a 100\% graft take compared to patients older than 60 years, with a $53 \%$ graft take. This may be because of the poor blood supply and the chronicity of the disease in the older patients. Anterior perforations had the lowest graft take. This is to be expected because anterior perforations are technically more challenging. They are difficult to reach and tend to have a poorer blood supply and positioning and stabilization of the graft to prevent medialization is technically more challenging. In this study, a wet moist ear and a middle ear musosa with granulations had a higher graft take (83\% each) than a dry ear (61\%). This may be explained by the increased blood supply of the mucosa in the presence of inflammation (wet moist ear and granulations) as well as the surgeon's technique. The surgeon made use of a number of adjuvant procedures to ensure successful graft take such as rinsing the middle ear with a solution of an antibiotic and a steroid, and the performance of cortical mastoidectomy where indicated. The sandwich technique had the highest success rate followed by the onlay-underlay technique in this study at $86 \%$ and $83 \%$ take, respectively. This is to be expected as both techniques give the most stability to the graft.

A good surgical technique with endoscopic visualization, combined with good graft material in the hands of an experienced surgeon, will give superior results. Dumbell perichondrial cartilage graft clip-on fits perfectly on the perforation, giving a very good outcome as reported in the literature. In fact, dumbell perichondrial cartilage has been the game changer in the successful repair of anterior perforations in the hands of the surgeon during the period under study until now (anecdotal findings).

On the other hand, factors that were statistically insignificant in affecting graft take included perforation size, graft material, the presence of comorbidities (diabetis

Table 6 Review of different prognostic factors $[4,5,17]$

\begin{tabular}{|c|c|c|c|}
\hline Factor & Yes & No & Comment \\
\hline 1. Age & $\begin{array}{l}\text { Sarkar, } 2009[3] \\
\text { Berger, } 1997[7] \\
\text { Adkins, } 2005\end{array}$ & $\begin{array}{l}\text { Sarkar, } 2009[3] \\
\text { Berger, } 1997[7] \\
\text { Podoshin, } 1996 \\
\text { Glasscock, } 1973[6] \\
\text { Albera, } 2006[5]\end{array}$ & $\begin{array}{l}\text {-Mixed opinion, } \\
\text {-Age does not matter } \\
\text {-Extreme ages has poor outcome (very young and very old) }\end{array}$ \\
\hline 2. Size & $\begin{array}{l}\text { Adkins, } 2005 \\
\text { Lee, } 2002[9] \\
\text { Denoyele, } 1999\end{array}$ & $\begin{array}{l}\text { Singh, } 2005[17] \\
\text { Pignataro, } 2001[18]\end{array}$ & $\begin{array}{l}\text {-Mixed opinion size does not matter } \\
-<50 \% \text { better than }>50 \% \text { perforation }\end{array}$ \\
\hline 3. Site of perforation & $\begin{array}{l}\text { Lee, } 2002[9] \\
\text { Lin, } 2008[4]\end{array}$ & $\begin{array}{l}\text { Singh, } 2005[17] \\
\text { Pignataro, } 2001[18]\end{array}$ & $\begin{array}{l}\text {-Mixed opinion, site does not matter } \\
\text {-Anterior perforation technical difficult (worse outcome) } \\
\text {-Posterior/inferior better outcome }\end{array}$ \\
\hline 4. Middle ear status Wet/dry & $\begin{array}{l}\text { Uyar, } 2006[20] \\
\text { Tos, } 1986 \\
\text { Albu, } 1998[15]\end{array}$ & $\begin{array}{l}\text { Sarkar, } 2009[3] \\
\text { Berger, } 1997[7] \\
\text { Podoshin, } 1996 \\
\text { Glasscock, 1973 [6] } \\
\text { Lin, 2008 [4] }\end{array}$ & $\begin{array}{l}\text {-Mixed opinion } \\
\text {-Dry for <3/12 better } \\
\text {-Status wet/dry no effect } \\
\text {-Higher take-up in wet ear better }\end{array}$ \\
\hline 5. Status of contra lateral Ear & $\begin{array}{l}\text { Uyar, } 2006[20] \\
\text { Ophir, } 1987[11] \\
\text { Koch, } 1990[12] \\
\text { Sarkar, } 2009[3] \\
\text { Lin, } 2008[4]\end{array}$ & $\begin{array}{l}\text { Chandrasekhar, } 1995 \text { [13] } \\
\text { Vartiainen, 1997 [21] } \\
\text { Sarkar, 2009 [3] } \\
\text { Lin, 2008 [4] }\end{array}$ & $\begin{array}{l}\text {-Mixed opinion } \\
\text {-Status plays no role bilateral Myringoplasty performed successfully }\end{array}$ \\
\hline 6. Graft material & Lin, $2008[4]$ & & -Worse outcome with temporalis fascia \\
\hline 7. Income status & Onal, 2005 & & -Higher income better success than low income \\
\hline 8. Technique onlay/underlay & Lin, 2008 [4] & & -Onlay has better success than Underlay \\
\hline 9. Anesthesia & Lin, $2008[4]$ & & -Local anesthesia has worse prognosis \\
\hline 10. Surgical approach & Lin, $2008[4]$ & & -Post/RetroAuricular has a better success rate \\
\hline 11. Eustacian Tube status & & Lin, $2008[4]$ & -Difficult to assess Eustachian Tube function and make a comment \\
\hline 12. Smoke & $\begin{array}{l}\text { Onal, } 2005 \\
\text { Becvarovski, } 2001\end{array}$ & & $\begin{array}{l}\text {-Affect healing of the graft (vascularity) } \\
\text {-Induces cough which may displace the graft during recovery period }\end{array}$ \\
\hline 13. Surgeon & Onal, 2005 & & Senior/experienced surgeon better success \\
\hline
\end{tabular}


mellitus and HIV), smoking, and eatiology. Although not statistically significant in this study, the graft take among non-smokers was higher (70\%) than that of smokers (50\%), underscoring the effects of smoking on healing. Iatrogenic perforations had the highest graft take (100\%) as expected because it is a fresh perforation. Although no agreement exists on the effect of various prognostic factors on graft take, the results of this study for most part correlated with literature findings [8-15].

Medical care globally is increasingly emphasizing the importance of the patient's perspective and input for each treatment offered. Holistic patient care requires evidence-based medicine. A team approach is considered best for the patient as the doctors are not the only role players concerning the patient's best interest. Patient expectations increase considerably, and in cases where there is poor communication or misunderstanding of expected outcomes, litigation is more likely to occur.

When properly planned, management of the perioperative expectations and outcomes between the patient and the surgeon allows the patient to communicate their main concerns and helps to improve patient care expectations [1-3]. The use of PROs is an attempt at improving patient care, communication, and patient perspectives in defining success after a surgical procedure. In this study, a significant association between patient and the surgeon level of satisfaction was found. Both the patient and surgeon were satisfied with the outcome of the operation process.

The global outcome satisfaction success score indicates an association between the satisfaction success scores evaluated in three categories: unsatisfied, satisfied, and very satisfied. The results between not satisfied, satisfied, and very satisfied catergories show a significant association between the patient and the surgeon, $P=0.001$. Thus, there is an agreement between patient and the surgeon outcomes relevant to patient perspective.

The study found that patients and surgeon are very satisfied with the level of drum repair compared to hearing improvement where there is relatively similar level of satisfaction. Furthermore there is a high of level dissatisfaction from both the patient and the surgeon on stopping discharge and stopping pain. Both patient and surgeon were satisfied with the outcome of the operation and the correlation results of $92 \%$ shows that there is good correlation in the outcome results. This study found that both patient and surgeon's level of satisfaction was excellent. The results further showed a strong association between the patient and the surgeon's level of satisfaction (chi-square test $=119,6754$ and $p$ value $=0.0001$ ). The chi-square test results (Table 5) confirm that the level of satisfaction the patients expressed closely correlates with the level of satisfaction expressed by the surgeon, and the level of dissatisfaction the patient has correlates to the level of dissatisfaction the surgeon expressed. This supports the call for a global success outcome measure obtained by combining the surgeon- and patientreported outcomes.

It is important that the surgeon success understanding of is defined. The patient's reported expected outcomes individualize the patients definition of success following surgery. A standardized scoring system would assist to define true global success following ear surgery. This would be a more accurate indicator of success following tympanoplasty.

\section{Conclusions}

The defining success following tympanoplasty, the patient- and surgeon-reported outcomes on agreed goals correlate very well statistically with regard to increased success and satisfaction rates. A global success outcome measure obtained by combining the surgeon- and patient-reported outcomes would be beneficial in reporting true global success following tympanoplasty. The surgeon and patient can set and agree on achievable outcome success satisfaction indicators before operation and reduce unrealistic expectations from patients and surgeon.

In this study assessing success in tympanoplasty, included the patient- and surgeon-reported outcomes, when considered against agreed goals and indications, correlate well statistically. In this cohort, the true global success very satisfied rate was $92 \%$ (chi-square test $=119$; $p=0.001<0.05)$ (Table 5) compared to $77 \%$ surgical success only, was based on graft take only. The combination of patient- and surgeon-reported outcomes would be beneficial in reporting true global satisfaction success rate in tympanoplasty and other otological procedures.

We also looked at our prognostic factors for success of tympanic membrane take-up depended on various prognostic factors as in literature (Table 6). Although no agreement exists on the effect of various prognostic factors on graft take, the results of this study generally correlated with literature findings [8-15].

All in all, a good surgical technique with endoscopic visualization, combined with good graft material in the hands of an experienced surgeon, will give superior results. Dumb bell perichondrial cartilage graft clip-ons fit perfectly on the perforation, giving a very good outcome as reported in the literature. In fact, dumbell perichondrial cartilage has been the game changer in the successful repair of anterior perforations in the hands of the surgeon during the period under study until now (anecdotal findings). 


\section{Abbreviations}

ABG: Air bone gap; HIV: Human immunodeficiency virus; MERI: Middle ear risk index; PRO's: Patient-reported outcome; SPITE: Surgical, prosthesis, infection, tissues, and Eustachian tube dysfunction.

\section{Acknowledgements}

I would like to acknowledge my secretaries Ms. Patricia Kgari and Bernadette Khoele for their input, typing, and revising the article. A special thanks to my scientific editor, Mrs. Livhu Mphaphuli for statistical work, and Ms. Liza Marx from Academic and Professional Editing Services (APES) for attending to the copy-editing and proofreading of this article. To all the patients who agreed to be part of the study, thank you all. My gratitude goes to everybody else who participated in this article creation, including my registrars.

\section{Author's contributions}

The author is a surgeon, researcher, writer, and formulation of the article and review of the whole work, conduct the study, and data collection. The author read and approved the final manuscript sent to scientific editor for editing.

\section{Funding}

Author personal funding

\section{Availability of data and materials}

The dataset used and/or analyzed during the current study are available from the author on reasonable request.

\section{Declarations}

Ethics approval and consent to participate

Consent to participate: Freely given, informed consent to participate in this study was obtained from participants (or their parents or legal guardian in case of children under legal age to consent).

Verbal consent from all patients was obtained, and all ethical protection and approval from participants and request for publication from ethics committee, Faculty of Medicine University of Pretoria ethics committee request to publish my clinical audit was requested as an audit personal study chart review. Reference number $868 / 2020$

\section{Consent for publication}

Was verbal obtained from patients during research audit and follow-up.

\section{Competing interests}

The author declares no competing interest.

Received: 11 October 2021 Accepted: 26 November 2021

Published online: 28 January 2022

\section{References}

1. Liu JB, Pusic AL, Temple LK, Koi CY. Patient-reported outcomes in surgery: listening to patients improves quality care. https://bulletin.facs.org/2017/ 03/.

2. Anderson JM, Wixson RL, Tsai D, Stulberg SD, Chang RW (1996) Functional outcome and patient satisfaction in total knee patients over age of 75. J Arthroplasty 11(7):831-840

3. Sarkar S, Roychoudhury A, Roychoudhuri BK (2009) Tympanoplasty in children: review article. Eur Arch Otorhinolaryngol 266:627-633

4. Lin AC, Messner AH (2008) Pediatric tympanoplasty: factors affecting success. Curr Opin Otolaryngol Head Neck Surg 16:64-68

5. Albera R, Ferrero V, Lacilla M, Canale A (2006) Tympanoplasty reperforation in myringoplasty: evaluation of prognostic factors. Ann Otol Rhinol Laryngol 115(12):875-879

6. Glasscock ME (1973) Tympanic membrane grafting with fascia: overlays undersurface technique. Laryngoscope 83:754-770

7. Berger G, Ophir D, Berco E, Sade J (1997) Revision myringoplasty. J Laryngol Otol 111:517-520

8. Denoyelle F, Roger G, Chauvin P, Garabedian EN (1999) Myringoplasty in children: predictive factors of outcome. Laryngoscope 109:47-51
9. Lee P, Kelly G, Mills RP (2002) Myringoplasty: does size of the perforation matter? Clin Otolaryngol Allied Sci 27:331-334

10. Bhat NA, De R (2000) Retrospective analysis of surgical outcome, symptom changes and hearing improvement fallowing myringoplasty. J Otolaryngol 29:229-232

11. Ophir D, Porat M, Marshak G (1987) Myringoplasty in the pediatric population. Arch Otolaryngol Head Neck Surg 113:1288-1289

12. Koch WM, Friedman EM, McGill TJl et al (1990) Tympanoplasty in children. The Boston Children Hospital experience. Arch Otollaryngol Head Neck Surg 116:35-40

13. Chandrasekhar SS, House JW, Devgan U (1995) Pediatric tympanoplasty. A 10-year experience. Arch Otolarngol Head Neck Surg 121:873-878

14. Lau T, Tos M (1986) Tympanoplasty in children. Analysis of late results. Am J Otol 7:55-59

15. Albu S, Babighian G, Trabalzini F (1998) Prognostic factors in tympanoplasty. Am J Otol 19:136-140

16. Sade J, Berco E, Brown M, Weinberg J, Avraham S (1981) Myringoplasty: short and long-term results in a training program. J Laryngol Otol 95:653-665

17. Singh GB, Sidhu TS, Sharma A, Singh N (2005) Tympanoplasty type I in children: an evaluative study. Int J Pediatr Otorhinolaryngol 69:1071-1076

18. Pignataro L, Della Berta LG, Capaccio P, Zaghis A (2001) Myringoplasty in children: anatomical and functional results. J Laryngol Otol 115:369-373

19. Caylan R, Titiz A, Falcioni M et al (1998) Myringoplasty in children; factors influencing surgical outcome. Otolaryngol Head Neck Surg 118:709-713

20. Uyar Y, Keles B, Koc S et al (2006) Tympanoplasty in pediatric patients. Int J Pediatr Otorhinolaryngol 70:1805-1809

21. Vartiainen E, Vartiainen J (1997) Tympanoplasty in young patients: the role of adenoidectomy. Otolaryngol Head Neck Surg 117:583-585

\section{Publisher's Note}

Springer Nature remains neutral with regard to jurisdictional claims in published maps and institutional affiliations.

\section{Submit your manuscript to a SpringerOpen ${ }^{\circ}$ journal and benefit from:}

- Convenient online submission

- Rigorous peer review

- Open access: articles freely available online

- High visibility within the field

- Retaining the copyright to your article

Submit your next manuscript at $\boldsymbol{\nabla}$ springeropen.com 